\title{
Biotechnology Growth Partnership: A Potential Flagship Program in S\&T
}

\author{
Raju Adhikari and Benu Adhikari \\ NRN Skill, Knowledge and Innovation (SKI) Exchange Task Force, Non Resident Nepali Association (NRNA), www.nrn.org.np
}

\section{Correspondence Author:}

Raju Adhikari

E-mail: r_adhikari@hotmail.com

\section{Background}

Nepal is a land locked country with very few mineral resources. However, she is vastly rich in her diverse, native, high altitude flora and fauna from the tropical to subalpine region; well known for their high value in medicinal application. These natural resources have not been exploited to their full potential due to the lack of necessary expertise and required technical facilities needed for their full scientific investigation. Nepal is primarily an agricultural country and the Agriculture contributes to approximately $38 \%$ of Nepal's 31 B\$ GDP. In the past decade, there were many initiatives by government research agencies, private sectors and foreign agencies such as USAID and Rockefeller foundation to promote biotechnology and natural product research activities in Nepal. However, due to lack of policies and collaborations at an Institutional level, most of the R\&D work had remained focused only in the tissue culturing of few plants (medicinal/horticulture/ornamental) and fruits/ vegetables so far.

Nepal Academy of Science and Technology (NAST) and the Ministry of S\&T have strongly emphasized the need to promote innovation and collaboration in the above stated priority areas whilst working in partnership with

Raju Adhikari is currently working as a Principal Research Scientist at CSIRO Material Science and Engineering, Vic, Australia and is the chair of SKI Task force. Dr Benu Adhikari, is a member SKI task force and a Senior lecturer at University of Ballarat, Vic Australia overseas countries. The Nepal government has announced a new national plan for the biotechnology research by focusing on altitude medicinal plants and setting up a national biotechnology research and development centre to speed up research and encourage private sector participation. The plan recommends biotechnology courses and scholarships in Nepal's universities and provides financial incentives in tissue culture and genetic technologies to select and breed improved crop varieties, usage of microbial cultures to manage industrial waste, biosensors for monitoring soil and air pollutants, and scientific assessment of the country's bio diverse floras for use in pharmaceutical and cosmetic industries.

Biotechnology research globally and especially in countries like USA, UK, European Union, Australia, China and India have a proven track record of commercial success. Australia has signed an international Biotechnology growth partnership initiative with a few countries and such collaborations are expected to induce a great benefit to the economy of both countries through sharing of ideas, innovation and resources. Nepal Academy of Science and Technology (NAST) and Nepal Agriculture Research Council (NARC) have shown interest in developing such partnerships with Australia and overseas organizations to help Nepal biotechnology Industry in Agriculture and Health sectors. Recently, NRNA and NAST have signed a memorandum of understanding (MoU) in S\&T field to work jointly in national priority areas such as Biotechnology and Environment. This will allow NAST, NRNA and other scientific institutions in Nepal to work jointly on collaborative projects and submit proposals 
to interested overseas Biotechnology companies and research organizations for funding.

\section{Potential Project Area}

Nepal's high altitude herbal medicinal plants are native and unique to geo-climatic regions and have potential niches for the global market. Nepal currently trades about 36 different types of products derived from herbal plants and the total revenue earned is reported to be approximately 12 million NRs (US \$240,000). Around $98 \%$ raw products are exported to Dabur India, a leader in manufacturing/marketing herbal, naturebased products in Asia. Due to the lack of any patent protection alongside the Governments weak policy on farming and trade of medicinal plants, the revenue source from these herbal medicinal plants are mostly from the selling of raw products. In Nepal Ayurvedic Industries are also selling mostly the raw materials without any value added research input and thus contributing very little to the country's economy (NTFP Trade Bulletin, 2005)

Biotechnology Growth Partnership could be initiated as a long term collaborative project in the above mentioned areas. The project could aim to commercially exploit high altitude flora such as Yarsha Gumba (Cordyceps sinensis) (Figure 1) by carrying out research tailored to value add by conducting rapid high throughput bioassay screenings against certain specific target diseases and developing appropriate formulations for its use as a common medicines and health products [1-9]. A medicinal herb of illustrious history known as Himalayan Viagra has been well documented in the literature for its use as a drug to boost immune system, anti-ageing and aphrodisiac properties. Only 3 species of the caterpillar fungus are reportedly found in Nepal at a reserve $\sim 4,900 \mathrm{~m}$ with $50 \%$ collection coming from Dolpa region alone. The raw materials collected in this manner are exported to Tibet, China and other countries. Government had legalized the trade of raw material in 2001 and imposed a royalty of $\$ 280 / \mathrm{kg}$ whereas the global Market price currently stands between US\$ 3, 000/kg for the lowest quality to over US\$18, 000/Kg for the highest quality larvae. The project will also aim to establish a National Germplasm bank of flora of high medicinal values to protect their genetic diversity.

Similarly in Food biotechnology, Yak cheese could be used as a valuable resource due to its low fat (26\%), high protein $(26 \%)$ and non conjugated linoleic acid (CLAs) content compared to cow cheddar cheese (see Table 1). The above fatty acid is reported to posses anticancer and anti Type T2 diabetes properties [1015). A project proposal to address its large scale production, assess scientific effectiveness and quality control could help diary food industries and bring huge economic benefit to the farming community.

Furthermore, in a country like Nepal, where large quantity of fruits are wasted due to lack of infrastructure (processing, storage, transportation), a project focused to converting these fruits into powders without compromising their nutritional value could help food industry in a big innovative way. A research team led by a NRN STF team member Dr. Benu Adhikari (University of Ballarat, Victoria, Australia) has developed some breakthrough technologies in this area.

There are many other potential areas in agriculture where such collaboration could be initiated. SKI takes this opportunity to invite our NRN professionals who are working in the Biotechnology field to come forward and contribute in this new venture initiative of S\&T stream.

\section{Path to Market}

The collaboration initially could focus on high altitude native medicinal plants in order to develop common drugs and cosmetic products for pharmaceutical industries. These types of products serve an advantage as they do not require stringent regulatory criteria and are an easy path to the market. The products based on developed formulation from the above project can be manufactured and marketed as a common drug and can be sold under the patent/trade rights to guarantee its claim. Nepal's commitment will be to provide raw materials and manpower and conduct preliminary screening research while advanced testing and formulation matrix could be carried out in Australia. The clinical trials and manufacturing of products could be carried out in Nepal which will help develop necessary infrastructure for the production of such value added products and clinical trial facilities in the long run on low cost. The patent royalties will be shared and $10 \%$ of profit from the sale of such product can be reinvested in $R \& D$ to develop further advanced technologies or to extend research in other potential areas. The life of the above flagship project could be 
approximately 3-5 years to allow patent protection and development work.

\section{Approach}

NRN SKI team is working closely with Nepal Academy of Science and Technology in Nepal to develop a joint collaborative project proposal to explore fund from potential investors or overseas S\&T organisations. The S\&T organisations in Nepal will provide commitment to raw materials, manpower and facilities to conduct preliminary research work and the advanced testing and formulation development work could be carried

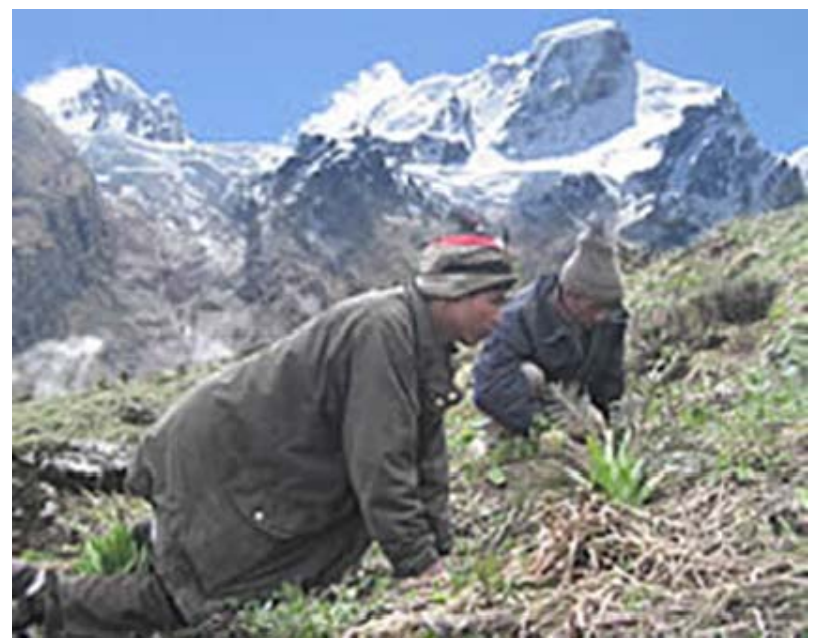

Figure 1. (a) Dolpa community collecting Yarsha Gumba, out overseas. Final formulation trials and manufacturing of such value added products will be carried out in Nepal (cheap resources) to help develop research infrastructure. The patent will be shared depending upon the nature of the agreement and Nepal will get the dollar value from the royalty obtained from the sale of such products. NRNA will lobby Nepal government to provide tax incentives and other flexibility for establishment of any spin-off company arising from such an investment. A general scheme of research approach is given in Figure 2 .

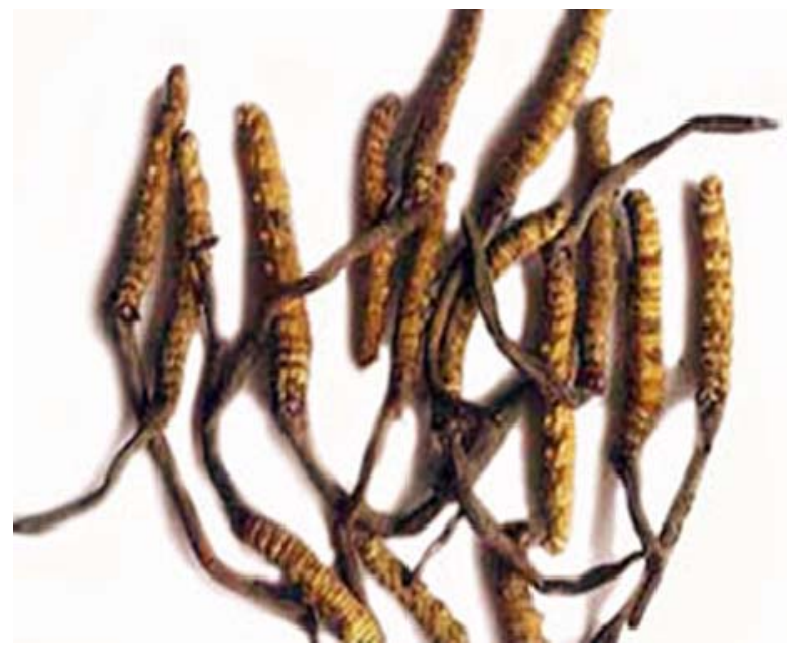

Figure 1. (b) a raw specimen of Yarsha Gumba

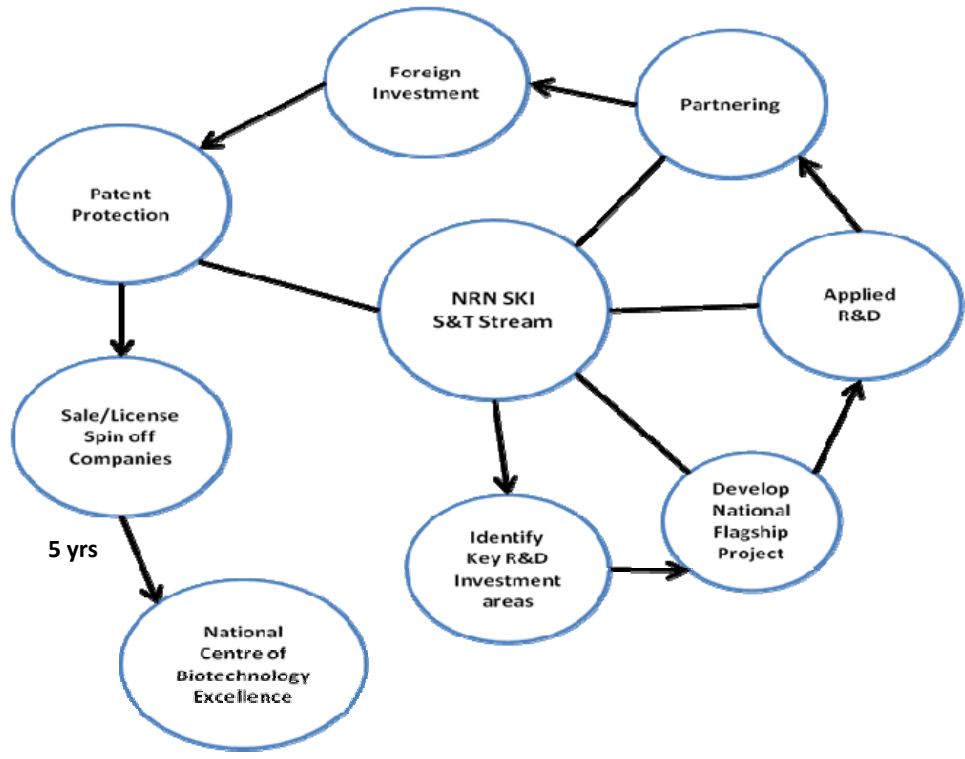

Figure 2. A general scheme of approach in Flagship projects

Table 1. A comparison of cheese composition of Yak and Cow's milk

\begin{tabular}{|l|l|l|}
\hline Fatty acid & Yak cheese & Cow-cheddar cheese \\
\hline cis-9, trans-11 CLA & $2.01 \pm 0.07$ & $0.48 \pm 0.07$ \\
\hline trans-9, cis-11 CLA & $0.13 \pm 0.01$ & $0.03 \pm 0.01$ \\
\hline trans-10, cis-12 CLA & $0.038 \pm 0.001$ & $0.009 \pm 0.001$ \\
\hline trans-11, trans-13 CLA & $0.039 \pm 0.001$ & $0.018 \pm 0.001$ \\
\hline trans-9, trans-11 CLA + trans-10, trans-12 CLA & $0.057 \pm 0.003$ & $0.031 \pm 0.003$ \\
\hline
\end{tabular}




\section{Expected Outcome}

The above conceived research programs will bring innovation and expertise to Nepal and help in conducting applied research activities to asses' the scientific effectiveness of the above mentioned resources and value add the product for their commercial exploitation. The above mentioned research streams will generate new patents and publications. The revenue will be generated by licensing the technology or through spin off companies with the royalties that can be shared mutually. Such collaborative research programs will build strong, longer term partnership between Nepal and overseas institutions in the field $S \& T$ and extend the collaborations further in other areas of commercial potentiality. Nepal as well as the collaborating partner country stands to win from these ventures. The S\&T stream will also explore and help conduct a feasibility study to establish a National Biotechnology Centre of

\section{References}

Adhikari, M. K., 2008. The medicinal fungi from Nepal. Pp. 107-118. In: Jha, P. K., Karmacharya, S. B., Chhetri, M. K., Thapa, C. B., Shrestha, B. B., Eds, Medicinal Plants in Nepal: An Anthology of Contemporary Research, Ecological Society, Kathmandu, Nepal.

Bok, J. W. Lermer, L., Chilton, J., 1999. Antitumor sterols from the mycelia of Cordyceps sinensis. Phytochemistry, 51, 891898.

Chen, Y. Q., Hu, B., Xu, F., Zhang, W., Zhou, H., Qu, H. L., 2004. Genetic variation of Cordyceps sinensis, a fruitbody producing entomopathogenic species from different geographical region in China. FEMS Microbioliological Letttter, 230, 153-158.

Dong, C.-H., Yao, Y.-J.2008. In vitro evaluation of antioxidant activities of aqueous extracts from natural and cultured mycelia of Cordyceps sinensis. LWT, 41, 669-677.

Koh, J. H., Kim, J. M., Chang, U. J., Sub, H. J., 2003. Hypocholesterolemic effect of hot water extract from mycelia of Cordyceps sinensis. Biol. Pharm. Bull. 26, 84-87.

Koh, J. H., Yu, K.W., Shu, H. J., Choi, Y. M., Ahn, T.S., 2002. Activation of macrophages and the intestinal immune system by an orally administrated decoction from culture mycelia of Cordyceps sinensis. Bioscience, Biotechnology and Biochemistry, 66 (2), 407-411.

Li, S. P., Li, P., Dong, T. T. X., Tsim, K. W. K., 2001. Antioxidation activity of different types of natural Cordyceps sinensis and cultured Cordyceps mycelia. Phytomedicine, 8 , 207-212.
Excellence, lobby with the Government to formulate a Biotechnology policy and help establish a separate Biotechnology department under Ministry of S\&T.

\section{Risk Factor}

The current political instability, lack of collaborative agreements and the absence of commercial focus, poor governance and funding of S\&T projects, long term commitment, poor private sector participation and the absence of clear S\&T plan are some of the factors that may undermine confidence of stakeholders. Because of these reasons the government needs to provide better initiatives and assurance to protect such investment by brining a special legislation in S\&T investment. The S\&T organisations in Nepal are interested to enter into such a partnership program and by signing MoU with NAST; NRNA has shown its commitment to provide a helping hand and work in partnership to achieve the above goals.

Shrestha, B., Lee, W.-H., Han, S.-K., Sung, J.-M., 2006. Observations on some of the mycelia growth and pigmentation characteristics of Cordyceps militaris isolates. Mycobiology, 34, 83-91.

Zhu, J. S., Halpern, G. M., Jones, K., 1998. The scientific rediscovery of an ancient Chinese herbal medicine: Cordyceps sinensis: Part I. J. Alt. Comp. Med. 4 (3), 289303.

Fatty Acid Composition of Yak (Bos grunniens) Cheese Including Conjugated Linoleic Acid and trans-18:1 Fatty Acids; Mamun M. Or-Rashid, Nicholas E. Odongo, Bhishma Subedi, Pralhad Karki and Brian W. McBride' Department of Animal and Poultry Science, University of Guelph, Guelph, Ontario, Canada N1G 2W1; Asia, Agric. Food Chem., 2008, 56 (5), pp 1654-1660.

The big cheese "Nepal is perfect for cheese production. You couldn't ask for more, Nepali Times, " FROM ISSUE \#427 (28 NOV 2008 - 04 DEC 2008).

High Hill Yak Cheese Production in Nepal: An Analysis of Privatization Policy Incorporating the Impacts of Market Failures or Agro-Industries in Developing Countries, by Luke A. Colavito, Virginia Polytechnic Institute and State University, July 8, 1997.

Yak Cheese: Exotic, but Healthy? Cheese From Grass-Fed Yaks May Have Better Fatty Acid Profile Than Cheese From Grain-Fed Cows, Study Shows, By Miranda Hitti, WebMD Health News, WEBMED, March 14,2008.

Yak Cheese Is a Miracle; http://news.softpedia.com/news/ Yak-Cheese-is-Better-for-the-Heart81087.shtml 